\title{
Responding to forest degradation: altered habitat use by Dian's tarsier Tarsius dianae in Sulawesi, Indonesia
}

\author{
Stefan Merker, Indra Yustian and Michael Mühlenberg
}

\begin{abstract}
As most of the pristine forests of South-east Asia have been lost, the ability of its animal species to coexist with humans becomes increasingly important. Dian's tarsier Tarsius dianae, one of the smallest primates, lives in forests of central Sulawesi, Indonesia that are experiencing a dramatic increase in degradation by humans. To evaluate the effects of anthropogenic disturbance on tarsiers we used a comprehensive approach to estimate habitat suitability for these nocturnal insecthunters. On four study plots along a gradient of human land-use we determined population densities, home range sizes, nightly path lengths and group sizes of $T$. dianae. In total we captured 71 individuals and radio-tracked 30 of these. In more undisturbed sites,
\end{abstract}

population densities were high and travel distances small. We found the smallest home ranges in slightly disturbed forest. In a heavily disturbed plantation densities were low, and ranges and nightly path lengths were large. These results show that undisturbed and slightly degraded forests are the most suitable tarsier habitats, and that focusing on different population parameters could lead to differing conclusions about the suitability of particular habitats.

Keywords Density, Dian's tarsier, habitat suitability, home range, Indonesia, Lore Lindu National Park, primates, radio-tracking, Sulawesi, Tarsius dianae.

\section{Introduction}

As the destruction and degradation of the world's tropical rainforests continues at an alarming rate (Collins et al., 1991), the fate of their wildlife becomes more uncertain. Some species face extinction, others undergo population decline but are able to survive at low densities, and some are even favoured by human activities (Collins et al., 1991; IUCN, 2004). As with other higher taxa (Brooks et al., 1999; Lockwood et al., 2000; Waltert et al., 2004) this is also true for primates (Johns \& Skorupa, 1987; Chapman \& Lambert, 2000). To develop conservation strategies a thorough understanding of species' habitat requirements is needed. To examine the long-term survival of primates facing the effects of human activities most studies have focused on population densities (Chapman, 1987; Johns \& Skorupa, 1987; Ganzhorn, 1999; Merker \& Mühlenberg, 2000). However, primate density does not always reflect habitat suitability

\footnotetext{
Stefan Merker* (Corresponding author) and Michael Mühlenberg Centre for Nature Conservation (Dept.1), Georg-August University Göttingen, Von-Siebold-Str.2, 37075 Göttingen, Germany. E-mail tarsius@gmx.net Indra Yustian Department of Biology, University of Sriwijaya, JI. Palembang-Prabumulih, km 32, Inderalaya, OKI, South Sumatra 30662 Indonesia.

${ }^{*}$ Current address: Institute of Anthropology, Johannes Gutenberg-University Mainz, Colonel-Kleinmann-Weg 2 (SB II), 55099 Mainz, Germany.

Received 12 November 2003. Revision requested 25 March 2004. Accepted 2 July 2004
}

(Mühlenberg, 1993), and indicators that depend on resource availability, such as home range and territory sizes, may be more useful. With sufficient food and other vital prerequisites, animals use and defend smaller areas (Brown \& Orians, 1970; Bolen \& Robinson, 1995; Heiduck, 2002) and thus, energy expenditure for food acquisition is minimized. Relatively large ranges and long distances travelled may be indicators of less than optimum living conditions.

Few previous studies have looked at tarsier survival under different disturbance regimes. Population densities of western tarsiers Tarsius bancanus in Borneo are highest in secondary vegetation (Niemitz, 1979). Spectral tarsiers Tarsius spectrum in northern Sulawesi occur in several kinds of habitats, with population densities varying according to study region, habitat type and altitude (MacKinnon \& MacKinnon, 1980). Dian's tarsiers Tarsius dianae are slightly more abundant in secondary than in primary forest, but in heavily disturbed habitat densities are considerably lower (Merker \& Mühlenberg, 2000).

For other prosimian primate species, findings vary. Ganzhorn $(1995,1999)$ reported better living conditions for several lemur species on Madagascar after selective logging than before. Population densities of the grey mouse lemur Microcebus murinus were found to be higher in primary than in secondary forest (Ganzhorn \& Schmid, 1998). In most cases, varying food availability and predation pressure were thought to be responsible for the differing densities. For tarsiers, no previous 
research has compared home range sizes, path lengths or group sizes between habitats.

The goal of this study was to examine ranging patterns of Dian's tarsiers along a gradient of human disturbance. Based on previous findings that tarsiers do well in secondary habitats, we wished to determine to what extent this species tolerates the effects of human activities and how the animals adapt to them.

\section{Study species}

Dian's tarsier Tarsius dianae is endemic to Sulawesi, Indonesia's fourth largest island. With head and body lengths of $12 \mathrm{~cm}$ and body weights of $c .100 \mathrm{~g}$, the six currently recognized tarsier species are amongst the smallest of primates. Sulawesi tarsiers live in small groups, of up to eight individuals, composed of an adult male, 1-3 adult females and their offspring. They usually spend the daylight hours at a group-specific sleeping site comprised mostly of strangling figs (MacKinnon \& MacKinnon, 1980; Gursky, 1995, 1998; Yustian, 2002; Merker, 2003). During the night they move through the undergrowth of the forest in search of live animal prey, feeding mainly on insects such as crickets, grasshoppers and moths. In the morning adult and subadult individuals frequently perform duet songs that strengthen group bonds and serve as a territorial advertisement (MacKinnon \& MacKinnon, 1980). Little is known about the predators of tarsiers, although Gursky (2000a, 2002a,b, 2003) suggested that birds of prey, civets and snakes are the main predators. T. dianae was described by Niemitz et al. (1991) and is categorized as Lower Risk: conservation dependent on the IUCN Red List (IUCN, 2004). It is still abundant in central Sulawesi but population sizes are declining (Merker et al., 2004).

\section{Study area}

We conducted this study at the north-eastern boundary of Lore Lindu National Park, Central Sulawesi, Indonesia, over July-December 2000 and February-December 2001. The ranger station Kamarora (altitude $660 \mathrm{~m}$ ), the type locality for $T$. dianae, was used as a base camp (Fig. 1). The climate of Kamarora is slightly seasonal with $>100 \mathrm{~mm}$ of rain per month in 10 out of 11 consecutive months in 2001. Temperatures fall to $19.5 \pm 1.0^{\circ} \mathrm{C}$ at night with the daily maximum averaging $32.9 \pm 1.3^{\circ} \mathrm{C}$ and almost no seasonal variation (Merker, 2003). The forest adjacent to the field station is characterized by a variety of human land uses. Although it is a National Park, the area is being exploited by humans. Farmers grow coffee and cocoa within the forest, loggers extract rattan and timber to sell at the market in Palu, the provincial capital, and bamboo is cut for house construction. Due to an increase in forest encroachment in 2001 even

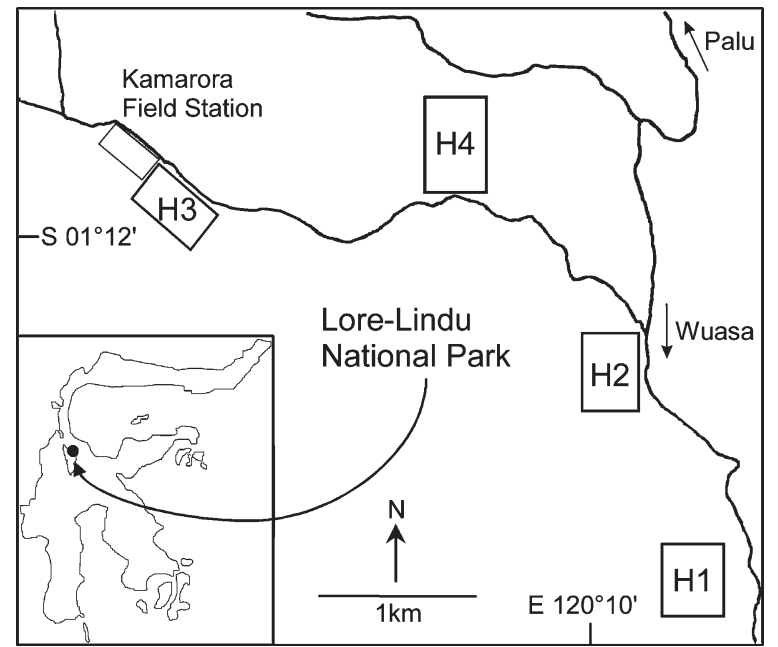

Fig. 1 Location of the study plots $\mathrm{H} 1-\mathrm{H} 4$ in the vicinity of Kamarora Field Station. The small road passing the ranger post marks the north-eastern boundary of Lore Lindu National Park. The inset map shows the island of Sulawesi and the location of the study area.

the old-growth forest patch included in this study is now no longer pristine. However, the results presented here were not influenced by this degradation as all data were collected before this change.

Four study plots were selected along a gradient of ongoing human disturbance (Fig. 1). The plots, of 10$20 \mathrm{ha}$, depending on the population density of tarsiers, were at least $2 \mathrm{~km}$ apart. One patch (H1) was virtually undisturbed old-growth forest, crossed only by a narrow overgrown path to a small forest garden far beyond this patch. In another (H2), slight anthropogenic effects were visible; it was criss-crossed by small trails and showed signs of small-scale bamboo Bambusa spp. and rattan Calamus spp. harvesting. One plot (H3) was characterized by an intermediate disturbance regime; interspersed with small forest gardens, it was also used for bamboo and rattan collection as well as selective logging. One heavily disturbed study plot (H4) was a mixed-species plantation outside the natural forest; it consisted mainly of small cocoa plantations with Gliricidia sepium as shade trees and interspersed patches of dense shrubs, bamboo, alang-alang Imperata cylindrica and corn Zea mays. Over the course of this study the level of human disturbance did not change significantly in any of the four plots. According to local farmers living at the forest margin human activities in the four plots had been unchanged for at least the previous 2 years. We therefore believe the data collected in this study are representative of the four habitat types.

\section{Methods}

To characterize disturbance, six parameters were used (Bynum, 1999): the number of sawn tree stumps, exotic 
plants, rattan palms, large trees (diameter at breast height $>50 \mathrm{~cm}$ ), epiphytes $<5 \mathrm{~m}$ above the ground, and the upper limit of moss growth on the trees. In each of the four study plots, 1610 * $10 \mathrm{~m}$ quadrats were randomly placed. The disturbance parameters were determined in each and then integrated into a disturbance index (described in Merker, 2003; Merker et al., 2004) to compare the relative intensities of anthropogenic influence.

At eight sample points in each plot the abundance of insects eaten by Sulawesi tarsiers (Nietsch, 1993; Tremble et al., 1993) was estimated using two methods: (1) To count moths, winged termites and mantids, a Petromax kerosene pressure lantern was fastened at $1.5 \mathrm{~m}$ in a small tree, and during the subsequent 5 min all visible insects with body length $>1 \mathrm{~cm}$ attracted by the light were counted; by differentiating the animals by species, size and location it was possible to avoid repeat counts of single specimens. (2) To count grasshoppers, crickets and cicadas, insects vocalizing within a $10 \mathrm{~m}$ radius around the sample point within $5 \mathrm{~min}$ were counted; repeated counts were avoided by noting specific vocalization patterns and the locations of individuals. At each of the eight sample points three replicate counts, each on a different evening, were made over 19.00-21.00.

In each plot as many tarsier groups as possible were located by triangulating, with the help of 2-5 field assistants at fixed points within a mapped trail system, the positions of vocalizing tarsiers during their morning duet songs. Over the course of several days, core areas of groups and often-used travel paths could be distinguished. By closing in on the animals, they could be followed to their sleeping sites, which were then mapped. For sites that were within the core area of each plot and whose three nearest neighbours were also within the plot, distances to the three nearest neighbouring groups were measured. The population density (number of groups per area) was calculated as density $=0.7698$ * groups/(mean distance) ${ }^{2}$. This formula, derived from the Delaunay triangulation (Krebs, 1999), is described in Merker (2003). It allows a transformation of unidimensional distance data to 2-dimensional area data. The advantage of this method lies in its independence from study plot boundaries, which are sometimes difficult to define.

Around tarsier sleeping sites, in the undergrowth normally utilized by the animals, 2-6 mist nets of 6-12 m length were positioned. Nets were open between 05.00 and 06.30 and / or between 17.00 and 19.00. As tarsiers are able to escape from a mist net, all nets were continually monitored to ensure a high capture success. After being caught in a net tarsiers were immediately removed and put in cotton bags. Thirty individuals (six adult females in each of the four study plots and six adult males in plot $\mathrm{H} 1)$ were tagged with $3.9 \mathrm{~g}$ radio-collars (PD-2C, Holohil
Systems Ltd., Carp, Canada) fastened around the waist. For comparability between plots, we focus here only on the 24 females. In plots $\mathrm{H} 1$ and $\mathrm{H} 2$ six females, one in each of six different groups, were tagged, whereas in plots $\mathrm{H} 3$ and $\mathrm{H} 4$ six females of five different groups were tagged (two females turned out to be members of the same family group, i.e. they shared a common sleeping site).

Each tarsier was radio-tracked over the course of c. 2 weeks. Tracking was at 04.00-06.30 (six sessions per animal), 18.00-22.00 (three sessions per animal), or overnight from 18.00-06.00 (once per animal), giving 75-80 locations for each tarsier. Positions of an animal were estimated by triangulating two consecutive bearings obtained within 2 minutes from different points. Home range sizes were calculated using the minimum convex polygon (Bearder \& Martin, 1980; White \& Garrott, 1990). During overnight tracking each tarsier was located every 15 min, giving c. 48 fixes per night. Nightly path length, i.e. the total distance a tarsier moved during 18.00-06.00, was calculated by summing up all distances between consecutive locations.

Group sizes and compositions were estimated by integrating capture data (the number of different tarsiers caught per sleeping site), direct observations of moving animals (the number of individuals seen at a time) and the records of morning duets (the number of tarsiers of each sex that called simultaneously from within the group territory). The following sex and age categories were distinguished: infants, body mass $<35$ g; juveniles, $<60 \mathrm{~g}$; subadult females, <95 g; subadult males, $<100 \mathrm{~g}$; adult females, $>95 \mathrm{~g}$; adult males, $>100 \mathrm{~g}$ and with descended testes. For individual recognition most non-radio-tagged tarsiers were marked with coloured plastic rings fastened around their elongated tarsus. Whenever possible, tarsal rings were removed after the study. Of the 30 radio-tracked tarsiers, 25 were recaptured and the collars retrieved. Due to illegal clear-cut logging that took place in $\mathrm{H} 1$ after data collection, five of the study animals could not be relocated even after an intensive search.

STATISTICA for Windows (StatSoft, Inc., 1999) was used for statistical analyses. All data sets were tested for normality using the Kolmogorov-Smirnov test. For normally distributed data, ANOVA and the Least Significant Difference Post Hoc Test were used, and the non-parametric Median Test was used to detect significant differences between habitats. Pearson's $r$ was used to test correlations between parameters. All tests were two-tailed (Sokal \& Rohlf, 1995).

\section{Results}

Altogether 71 Dian's tarsier were captured a total of 140 times. All results are presented in Table 1 . In each of H1, 
Table 1 Degree of disturbance (see text for details), number of groups/individuals studied (see text for details), group composition (mean numbers of individuals in each sex and age category; see text for details) and size, home range characteristics (mean area per individual, 'exclusive' area, nightly path length) and group and population densities of T. dianae, and insect abundances (mean numbers, with 3 replicates per sample point, of insects attracted by a strong light source within $5 \mathrm{~min}$, and insects vocalizing within a $10 \mathrm{~m}$ radius around the sample point within $5 \mathrm{~min}$ ) in the four habitat patches (H1-H4) in Lore Lindu National Park (see Fig. 1 for locations). Different letters denote significant differences between habitats (ANOVA, least significant difference test, $\mathrm{P}<0.05$ ).

\begin{tabular}{|c|c|c|c|c|}
\hline & \multicolumn{4}{|l|}{ Study patch } \\
\hline & $\mathrm{H} 1$ & $\mathrm{H} 2$ & H3 & $\mathrm{H} 4$ \\
\hline Degree of disturbance (\%) & 8 & 17 & 50 & 100 \\
\hline $\begin{array}{l}\text { No. groups/individuals studied } \\
\text { Group composition \& size }\end{array}$ & $6 / 6$ & $6 / 6$ & $5 / 6$ & $5 / 6$ \\
\hline Adult males & 1.0 & 1.0 & 1.0 & 1.0 \\
\hline Adult females & 1.7 & 2.2 & 1.4 & 1.2 \\
\hline Subadult males & 1.0 & 1.0 & 0.4 & 0.6 \\
\hline Subadult females & 0.5 & 0.7 & 0.6 & 0.4 \\
\hline Juveniles & 0.2 & 0.3 & 0.0 & 0.0 \\
\hline Infants & 0.3 & 0.0 & 0.0 & 0.0 \\
\hline $\begin{array}{l}\text { Mean group size } \pm \mathrm{SD} \text { (mode) } \\
\text { Home range } \mathcal{E} \text { densities }\end{array}$ & $4.7 \pm 0.8(4.5)$ & $5.2 \pm 1.9(5.5)$ & $3.4 \pm 1.1(3.0)$ & $3.2 \pm 1.1(3.0)$ \\
\hline Mean home range area \pm SD (ha) & $1.58 \pm 0.34^{\mathrm{ac}}$ & $1.08 \pm 0.45^{\mathrm{b}}$ & $1.10 \pm 0.09^{\mathrm{ab}}$ & $1.81 \pm 0.59^{c}$ \\
\hline Exclusive home range area (ha) & 0.34 & 0.21 & 0.32 & 0.57 \\
\hline Nightly path length \pm SD (m) & $945 \pm 190$ & $1,081 \pm 247$ & $1,030 \pm 331$ & $1,263 \pm 307$ \\
\hline Distance to nearest neighbours $\pm S D(m)$ & $116 \pm 18^{\mathrm{a}}$ & $145 \pm 14^{\mathrm{a}}$ & $142 \pm 11^{\mathrm{a}}$ & $234 \pm 129^{b}$ \\
\hline Group density (groups $\mathrm{km}^{-2}$ ) & 57 & 36 & 38 & 14 \\
\hline $\begin{array}{l}\left.\text { Population density (no. } \mathrm{km}^{-2}\right) \\
\text { Insect abundance }\end{array}$ & 268 & 187 & 129 & 45 \\
\hline Mean no. at light trap \pm SD (sample points) & $3.6 \pm 1.1(6)$ & $3.1 \pm 1.3(8)$ & $3.7 \pm 1.7(8)$ & $3.8 \pm 1.4(8)$ \\
\hline Mean no. vocalizing \pm SD (sample points) & $7.9 \pm 0.6^{\mathrm{a}}(6)$ & $9.0 \pm 0.6^{\mathrm{b}}(8)$ & $9.8 \pm 0.9^{b}(8)$ & $6.5 \pm 1.0^{c}(8)$ \\
\hline
\end{tabular}

H2 and $\mathrm{H} 3$ we located 10 or 11 sleeping sites, but only 5 in H4. Group sizes were not significantly different between the study plots (Median test, $\chi^{2}=3.66 \mathrm{df}=3$, $\mathrm{P}=0.30)$. The size of female home ranges varied significantly between the plots (ANOVA, $F_{3,20}=4.66, \mathrm{P}=0.01$ ) with smallest ranges at slight $(\mathrm{H} 2)$ and medium $(\mathrm{H} 3)$ disturbance regimes. By dividing the size of a home range by the number of group members, we computed the size of an 'exclusive' home range, i.e. a theoretical area that is used by a single tarsier and no other conspecific. This was smallest for tarsiers in H2, slightly larger in H1 and $\mathrm{H} 3$ and largest in heavily disturbed forest H4. Although path lengths were not significantly different between plots (ANOVA, $F_{3,20}=1.45, \mathrm{P}=0.26$ ), there was a positive correlation between path length and the degree of disturbance (Pearson $r=0.88, n=4, \mathrm{P}=0.06$ ). The average distance between the sleeping site of a group and the sleeping sites of its three nearest neighbouring groups differed significantly between plots (ANOVA, $\left.F_{3,19}=3.76, \mathrm{P}=0.03\right)$. Although the group density was similar in $\mathrm{H} 2$ and $\mathrm{H} 3$, the slightly larger groups in $\mathrm{H} 2$ gave a higher population density in this habitat. Population density decreased with increasing anthropogenic influences (Pearson $r=-0.96, n=4, \mathrm{P}=0.02$ ). There was no significant difference between plots in the number of insects attracted by light (2-way ANOVA, $\left.F_{3,26}=0.48, \mathrm{P}=0.70\right)$, but the abundance of vocalizing insects was significantly different (2-way ANOVA, $\left.F_{3,26}=24.69, \mathrm{P}=0.00\right)$.

\section{Discussion}

Home ranges of Dian's tarsier in Kamarora were smallest in slightly disturbed forest (H2), and significantly smaller than in undisturbed old-growth forest (H1) and heavily disturbed habitat (H4). Ranges in moderately disturbed forest (H3) were similar to $\mathrm{H} 2$. Within these two forest types the animals did not have to roam over and defend large areas. The largest ranges were in heavily disturbed forest (H4), a mixed-species plantation outside the natural forest.

A slightly different picture emerges when looking at nightly path lengths. Although travel distances were not significantly different between the forest types, there was a trend of increasing nightly path lengths with increasing disturbance. Dian's tarsiers in old-growth forest used a smaller fraction of their home range per night than in more disturbed habitats (Merker, 2003), and this explains 
the partially reversed rankings of home range size and nightly path length with degree of forest disturbance. White \& Garrott (1990) considered path length to be a better indicator for energy expenditure than home range, in which case tarsiers in undisturbed forest have to expend less energy per night than those in disturbed habitat. However, whilst path length may be the best direct indicator of short-term energy use, home range sizes could reflect the capability of habitats to replenish resources.

Larger tarsier groups may be an indicator of a higher carrying capacity of a particular habitat type. For this to be true, groups must be stable, free emigration possible, and there must be no scarcity of potential sleeping sites (Harcourt \& Nash, 1986). For mammals, food availability, predation pressure and reproductive condition are commonly described as the most important variables influencing group sizes (Krebs \& Davies, 1981; Dunbar, 1988; Kappeler \& Ganzhorn, 1993). As Gursky (2002a) confirmed these findings for spectral tarsiers in north Sulawesi, Dian's tarsier groups are probably limited by similar factors. Although Dian's tarsiers prefer to sleep in strangling figs, they are flexible in their choice of sleeping sites (Yustian, 2002; Merker, 2003). The availability of potential sleeping sites such as fig trees, bamboo stands, or dense shrubs did not appear to be a limiting factor in any of our study patches. Additionally, there was no evidence of predation. Thus, the role of predation pressure in structuring populations of Dian's tarsier cannot be assessed. As tarsier females give birth to only one offspring per year, and as they regularly 'park' the infants at secure spots (MacKinnon \& MacKinnon, 1980; Gursky, 1994, 2000a, 2002c, 2003) the number of young individuals (Table 1) is difficult to determine. Nevertheless, pregnant females were captured year-round and in all study habitats (Merker, 2003). Thus, there appears to be no seasonal variation in reproduction.

In this study, tarsier groups in undisturbed and slightly disturbed forests were slightly larger than in moderately and heavily disturbed habitats. However, as the observed differences were not significant, no clear inferences on habitat suitability for tarsiers can be drawn from these data on group size.

Home ranges of Dian's tarsiers that belong to the same group overlap extensively (Merker, 2003) and therefore the size of the 'exclusive' home range, a theoretical area assigned to a single tarsier, probably better reflects the space requirements of individuals than the mean observed home range size. Comparing exclusive home ranges between the four study plots, the apparent advantage of forest with medium disturbance (H3) over undisturbed forest (H1) diminishes, and $\mathrm{H} 2$ is the habitat where a tarsier needs least space. Therefore, interpreting home range size with respect to group size, slightly disturbed forest (H2) seems to be the most suitable environment for $T$. dianae.

Population densities of Dian's tarsiers decreased with increasing human influence, with 268 individuals $\mathrm{km}^{-2}$ in undisturbed forest and only 45 individuals $\mathrm{km}^{-2}$ in heavily disturbed plantations. A high number of animals per unit area is an often-used indicator of favourable conditions, and both group composition and distribution of the tarsiers were stable over the 1.5 years of this study (Merker, 2003). The plots were not crowded because of habitat loss elsewhere, and all were surrounded by more or less suitable tarsier habitat. Thus, focusing solely on population density, primary forest is the most important habitat for tarsier conservation. It is not clear what causes the lower abundance of tarsiers in the slightly disturbed habitats even though resources are plentiful. One possible reason may be the high susceptibility of these animals to visual and acoustic disturbance in their environment (Merker \& Mühlenberg, 2000).

Unlike body weights and proportions, and ectoparasite loads of Dian's tarsiers, which did not differ significantly between the four sites (Merker, 2003), home range size, nightly path length, group size and population density, discussed above, did not vary consistently across the four habitat types. No one of these measures alone can therefore be used to indicate which of the four levels of human disturbance are more suitable for Dian's tarsier. In general it appears that a limited amount of human disturbance does not pose a major threat to this tarsier. Tarsiers can adapt to traditional land uses such as small-scale agroforestry (coffee or cocoa as cash crops) or selective logging (Merker \& Mühlenberg, 2000). Slight disturbance may open up the forest canopy and result in a greater heterogeneity of the forest and subsequently a higher arthropod diversity and density. Insect abundance was found to be highest in the slightly disturbed habitats, $\mathrm{H} 2$ and $\mathrm{H} 3$, and lowest in the mixed-species plantation $\mathrm{H} 4$. The increased prey density in $\mathrm{H} 2$ and $\mathrm{H} 3$ may balance the adverse effects of selective logging and acoustic disturbance at these sites (Merker \& Mühlenberg, 2000). If human disturbance is excessive, however, living conditions for tarsiers appear to deteriorate (as in H4). Another habitat factor influencing tarsier distribution is the availability of plant supports for locomotion, which is highest in the slightly and moderately disturbed habitats $\mathrm{H} 2$ and H3 (Merker, 2003).

Logging, rather than a limited amount of human disturbance, poses the most serious threat to these animals (Merker \& Mühlenberg, 2000). Not only does it clear potential sleeping sites but it also commonly opens up the forest to other forms of land-use, such as cashcrop plantations, cattle farming, or permanent human settlement.

There are some potential limitations to our study. Firstly, due to the logistic difficulty of locating, capturing 
and radio-tracking tarsiers in all habitats simultaneously, $\mathrm{H} 1$ to $\mathrm{H} 4$ were investigated in succession, and thus possible seasonal effects could have influenced our findings. Home range sizes of spectral tarsiers in north Sulawesi are, for example, dependent on seasonal changes in arthropod abundance due to marked seasonality of precipitation (Gursky, 2000b). However, rainfall and prey supply in central Sulawesi are both more evenly distributed throughout the year (Merker, 2003). Repeated radio-tracking of specific individuals of Dian's tarsier in both field seasons and over the course of several months revealed no consistent variation in home range sizes, and there was no marked reproductive season (Merker, 2003). Secondly, home ranges of tarsiers were computed over the course of 2 weeks, and as the same procedure was followed for the entire study, comparisons can be made between different habitats. However, tracking the same animals over the course of a significantly longer period could result in larger estimates of home range.

Our findings emphasize the importance of a comprehensive approach when studying primates. For Sulawesi tarsiers different methods of estimating habitat suitability generated different outcomes. Considering the importance of slightly degraded habitats for these animals, conservation efforts based solely on a comparison of population densities might result in allocating scarce funds ineffectively. Human population pressure on Sulawesi's remaining forests is high, and pristine patches are increasingly difficult to preserve. Hence, local governments and conservation biologists should strive to channel human land use into less damaging forms such as small-scale agroforestry. Many farmers wrongly suppose that tarsiers feed on cash crops. An educational campaign introducing their potential role as natural predators of insects and stressing their importance for ecotourism could greatly increase the tarsiers' chances of survival. Additionally, it is essential to safeguard potential sleeping sites such as dense shrubs, bamboo stands and strangling figs. Maintaining comprehensive tracts of undergrowth as well as minimizing the use of chemical pesticides is also vital for tarsiers' survival.

\section{Acknowledgements}

We thank the Indonesian Institute of Sciences (LIPI) as well as PKA, PHPA, BTNLL, POLRI, SOSPOL and other authorities for research permits. Further thanks are due to Jatna Supriatna and Noviar Andayani of the University of Indonesia, Jakarta, for officially sponsoring this study. Numerous field assistants supported us during data collection, and three anonymous reviewers commented helpfully on earlier drafts of this paper. The study was supported by scholarships from the German Academic Exchange Service and the German National Academic Foundation (to SM).

\section{References}

Bearder, S.K. \& Martin, R.D. (1980) The social organization of a nocturnal primate revealed by radio-tracking. In A Handbook on Biotelemetry and Radio-tracking (eds C.J. Amlaner \& D.W. MacDonald), pp. 633-648. Pergamon Press, Oxford, UK.

Bolen, E.G. \& Robinson, W.L. (1995) Wildlife Ecology and Management. 3rd edition. Prentice Hall, Englewood Cliffs, USA.

Brooks, T.M., Pimm, S.L., Kapos, V. \& Ravilious, C. (1999) Threat from deforestation to montane and lowland birds and mammals in insular South-east Asia. Journal of Animal Ecology, 68, 1061-1078.

Brown, J.L. \& Orians, G.H. (1970) Spacing patterns in mobile animals. Annual Review of Ecology and Systematics, 1, 239-262.

Bynum, D.Z. (1999) Assessment and monitoring of anthropogenic disturbance in Lore Lindu National Park, Central Sulawesi, Indonesia. Tropical Biodiversity, 6, 43-57.

Chapman, C.A. (1987) Selection of secondary growth areas by vervet monkeys (Cercopithecus aethiops). American Journal of Primatology, 12, 217-221.

Chapman, C.A. \& Lambert, J.E. (2000) Habitat alteration and the conservation of African primates: case study of Kibale National Park, Uganda. American Journal of Primatology, 50, 169-185.

Collins, N.M., Sayer, J.A. \& Whitmore, T.C. (eds) (1991) The Conservation Atlas of Tropical Forests: Asia and the Pacific. Macmillan Press, London, UK.

Dunbar, R. (1988) Primate Social Systems. Cornell University Press, Ithaca, USA.

Ganzhorn, J.U. (1995) Low-level forest disturbance effects on primary production, leaf chemistry, and lemur populations. Ecology, 76, 2084-2096.

Ganzhorn, J.U. (1999) Lemurs as indicators for assessing biodiversity in forest ecosystems of Madagascar: why it does not work. In Biodiversity in Ecosystems (ed. A. Kratochwil), pp. 163-174. Kluwer Academic, Dordrecht, The Netherlands. Ganzhorn, J.U. \& Schmid, J. (1998) Different population dynamics of Microcebus murinus in primary and secondary deciduous dry forests of Madagascar. International Journal of Primatology, 19, 785-796.

Gursky, S. (1994) Infant care in the spectral tarsier (Tarsius spectrum), Sulawesi, Indonesia. International Journal of Primatology, 15, 853-853.

Gursky, S. (1995) Group size and composition in the spectral tarsier, Tarsius spectrum: implications for social organization. Tropical Biodiversity, 3, 57-62.

Gursky, S. (1998) Conservation status of the spectral tarsier Tarsius spectrum: population density and home range size. Folia Primatologica, 69(supplement 1), 191-203.

Gursky, S. (2000a) Allocare in a nocturnal primate: data on the spectral tarsier, Tarsius spectrum. Folia Primatologica, 71, 39-54.

Gursky, S. (2000b) Effect of seasonality on the behavior of an insectivorous primate, Tarsius spectrum. International Journal of Primatology, 21, 477-495.

Gursky, S. (2002a) Determinants of gregariousness in the spectral tarsier (Prosimian: Tarsius spectrum). Journal of Zoology, 256, 401-410.

Gursky, S. (2002b) Predation on a wild spectral tarsier (Tarsius spectrum) by a snake. Folia Primatologica, 73, 60-62.

Gursky, S. (2002c) The behavioral ecology of the spectral tarsier, Tarsius spectrum. Evolutionary Anthropology, 11, 226-234. 
Gursky, S. (2003) Predation experiments on infant spectral tarsiers (Tarsius spectrum). Folia Primatologica, 74, 272-284.

Harcourt, C.S. \& Nash, L.T. (1986) Social organization of galagos in Kenyan coastal forests: I. Galago zanzibaricus. American Journal of Primatology, 10, 339-355.

Heiduck, S. (2002) The use of disturbed and undisturbed forest by masked titi monkeys Callicebus personatus melanochir is proportional to food availability. Oryx, 36, 133-139.

IUCN (2004) 2004 IUCN Red List of Threatened Species. IUCN, Gland, Switzerland [http://www.redlist.org, accessed 22 November 2004].

Johns, A.D. \& Skorupa, J.P. (1987) Responses of rainforest primates to habitat disturbance: a review. International Journal of Primatology, 8, 157-191.

Kappeler, P. \& Ganzhorn, J. (1993) Lemur Social Systems and their Ecological Basis. Plenum Press, New York, USA.

Krebs, C.J. (1999) Ecological Methodology. 2nd edition. Benjamin Cummings, Menlo Park, USA

Krebs, J.R. \& Davies, N.B. (1981) An Introduction to Behavioural Ecology. Blackwell Scientific, Oxford, UK.

Lockwood, J.L., Brooks, T.M. \& McKinney, M.L. (2000)

Taxonomic homogenization of the global avifauna. Animal Conservation, 3, 27-35.

MacKinnon, J. \& MacKinnon, K. (1980) The behavior of wild spectral tarsiers. International Journal of Primatology, $\mathbf{1}$, 361-379.

Merker, S. (2003) Vom Aussterben bedroht oder anpassungsfähig? Der Koboldmaki Tarsius dianae in den Regenwäldern Sulawesis. $\mathrm{PhD}$ thesis, University of Göttingen, Germany [available at http://webdoc.sub.gwdg.de/diss/2003/merker, accessed 22 November 2004].

Merker, S. \& Mühlenberg, M. (2000) Traditional land-use and tarsiers - human influences on population densities of Tarsius dianae. Folia Primatologica, 71, 426-428.

Merker, S., Yustian, I. \& Mühlenberg, M. (2004) Losing ground but still doing well - Tarsius dianae in human-altered rainforests of Central Sulawesi, Indonesia. In Land Use, Nature Conservation and the Stability of Rainforest Margins in Southeast Asia (eds G. Gerold, M. Fremerey \&

E. Guhardja), pp. 299-311. Springer, Heidelberg, Germany. Mühlenberg, M. (1993) Freilandökologie. 3rd edition. Quelle \& Meyer, Heidelberg, Germany.

Niemitz, C. (1979) Outline of the behavior of Tarsius bancanus. In The Study of Prosimian Behavior (eds G.A. Doyle \& R.D. Martin), pp. 631-660. Academic Press, New York, USA.
Niemitz, C., Nietsch, A., Warter, S. \& Rumpler, Y. (1991) Tarsius dianae: a new primate species from Central Sulawesi (Indonesia). Folia Primatologica, 56, 105-116.

Nietsch, A. (1993) Beiträge zur Biologie von Tarsius spectrum in Sulawesi. PhD thesis, Free University Berlin, Germany.

Sokal, R.R. \& Rohlf, F.J. (1995) Biometry. 3rd edition. Freeman, New York, USA.

StatSoft, Inc. (1999) STATISTICA for Windows. Tulsa, USA.

Tremble, M., Muskita, Y. \& Supriatna, J. (1993) Field observations of Tarsius dianae at Lore Lindu National Park, Central Sulawesi, Indonesia. Tropical Biodiversity, 1, 67-76.

Waltert, M., Langkau, M., Maertens, M., Härtel, M., Erasmi, S. \& Mühlenberg, M. (2004) Predicting losses of bird species from deforestation in Central Sulawesi. In Land Use, Nature Conservation and the Stability of Rainforest Margins in Southeast Asia (eds G. Gerold, M. Fremerey \& E. Guhardja), pp. 327340. Springer, Heidelberg, Germany.

White, G.C. \& Garrott, R.A. (1990) Analysis of Wildife Radio-tracking Data. Academic Press, San Diego, USA.

Yustian, I. (2002) Pohon tempat tidur dan kepadatan relatif populasi Tarsius dianae Niemitz et al. 1991 pada habitat yang terpengaruh aktivitas manusia di Taman Nasional Lore Lindu, Sulawesi Tengah. MSc thesis, University of Indonesia, Jakarta, Indonesia.

\section{Biographical sketches}

Stefan Merker has been studying eastern tarsiers for several years. His main research interests include tarsier ecology (particularly their habitat requirements), biogeography and phylogeny, and the population ecology of other vertebrates, as well as the transfer of scientific results to practical species management.

Indra Yustian has studied the population densities and sleeping tree choice of Tarsius dianae, and is now studying the ecology and conservation of T. bancanus.

Michael Mühlenberg's research and teaching activities cover many aspects of wildlife conservation, and in particular conservation strategies, monitoring programmes and ecological field methodology. 